Revue bibliographique pour le domaine irano-aryen

\title{
Regula Forster, Neguin Yavari (eds.). Global Medieval: Mirrors for Princes Reconsidered
}

\section{Denise Aigle}

\section{Q OpenEdition}

1 Journals

\section{Édition électronique}

URL : http://journals.openedition.org/abstractairanica/47167

DOI : 10.4000/abstractairanica.47167

ISBN : 1961-960X

ISSN : 1961-960X

Éditeur :

CNRS (UMR 7528 Mondes iraniens et indiens), Éditions de l'IFRI

Référence électronique

Denise Aigle, « Regula Forster, Neguin Yavari (eds.). Global Medieval: Mirrors for Princes Reconsidered », Abstracta Iranica [En ligne], Volume 37-38-39 | 2018, document 10, mis en ligne le 30 décembre 2018, consulté le 26 septembre 2020. URL : http://journals.openedition.org/abstractairanica/47167 ; DOI : https://doi.org/10.4000/abstractairanica.47167

Ce document a été généré automatiquement le 26 septembre 2020

Tous droits réservés 


\title{
Regula Forster, Neguin Yavari (eds.). Global Medieval: Mirrors for Princes Reconsidered
}

\author{
Denise Aigle
}

\section{RÉFÉRENCE}

Regula Forster, Neguin Yavari (eds.). Global Medieval: Mirrors for Princes Reconsidered.

Boston: Harvard University Press, 2015, i-vi, 228 p. (Ilex Foundation Series 15)

Ce volume est un nouveau témoignage de la vitalité des recherches sur les traités de conseils au prince et d'éthique gouvernementale, comme en attestent quelques récentes publications (Negin Yavari, Advice for the Sultan. Prophetics Voices and Secular Politics in Medieval Islam, Oxford, Oxford University Press, 2014 ; Louise Marlow, Counsel for Kings. Wisdom and Politics in Tenth-Century Iran. The Nașihat al-Mulūk of Pseudo-Māwardī, 2 vols, Edinburgh, Edinburgh University Press, 2016). Dans l'introduction (p. 1-10), les éditrices expliquent que ce type de littérature produite à l'époque médiévale tire son origine du traité de conseils supposé écrit pour Alexandre le Grand et, en Europe, la version latine de ce texte, le Secretum secretorum, lui-même basé sur un original arabe, Kitāb Sirr al-asrār. Elles expliquent que l'objectif de ce livre consiste à : «bring together eleven essays that cut temporal, geographical and cultural divides to address ideas about power, and inquired into the relationship between different intellectual traditions » (p. 1). Nous ne rendrons compte ici que des articles qui concernent cette littérature en Iran.

Hinrich Biesterfeldt ( $I$ Ibn Farīghūn's Jawāmi' al-'ulūm: Between Classification of Sciences and Mirror for Prince ", p. 11-25) qualifie l'auteur de ce texte comme un homo unis libri car nous ne savons presque rien de lui. Le Jawāmi' al-'ulūm est une classification de tous les savoirs que doit connaître un secrétaire du milieu du $\mathrm{X}^{\mathrm{e}}$ siècle. Un des trois manuscrits connus du Jawāmi` al-'ulüm est dédicacé au souverain de la 
province de Chaghāniyān, sur la rive droite de l'Oxus. L'analyse du texte conduit Biesterfeldt à démonter que la section concernant les vertus du souverain (bodly virtue, mental virtue, virtue due to nobility and dignity), toutes caractéristiques de la littérature des miroirs, ont pour origine la Grèce antique.

Dans «Aetiologies of the Kalila wa Dimna as Mirror for Prince» (p. 42-57), Olga M. Davidson s'intéresse aux récits contenus dans le célèbre ouvrage de fables animales, Kalïla wa Dimna. Avant d'examiner la transmission des récits, l'auteur décrit l'ouvrage, découpé en plusieurs structures constituées sept à dix récits dont l'origine va bien audelà de la tradition orale. Elle étudie ensuite comment ces récits ont été intégrés dans la littérature islamique, mais aussi en Europe. Elle montre que l'intégration des fables de Kalila wa Dimna dans différentes sociétés a influencé leur contenu pour les adapter à des contextes culturels nouveaux.

Partant du concept élaboré par Charles de Foucault qui considère que le livre résulte du processus qui représente un des modèles de ce que l'on peut appeler une «fonction auteur» ("What Is an Author?», dans Language, Counter-Memory Practice: Selected Essays and Interviews, Donald F. Bouchard, 1977, p. 113-138), Seyed Sadegh Haghighat («Persian Mirrors for Princes: Pre-Islamic and Islamic Mirrors Compared», p. 83-93) propose une analyse originale de l'influence de la tradition préislamique sur les miroirs rédigés en contexte islamique. Il étudie la plus ancienne tradition de l'aura de la royauté telle qu'elle est présentée dans les bas-reliefs de Naqsh-i Rustam (attestations textuelles et iconographiques). Il analyse le sens du terme " farra » (aura) et « khshathra » (gouvernance) pour montrer que les miroirs islamiques ne se sont pas développés comme une simple imitation des traditions iraniennes, mais qu'ils furent influencés par leur propre contexte politique et religieux.

5 La contribution de Mohsen Zakeri («A Proposal for the Classification of Political Literature in Arabic and Persian: Folk Narrative as a Source of Political Thought? », p. 174-197) clôt parfaitement le volume. L'auteur effectue une présentation et une classification des différents types de textes en relation (au sens large) avec l'éthique gouvernementale: philosophie politique (Aristote, Platon, al-Kindī, etc.), histoire politique et administrative (al-Fakhī fì ādāb al-sulțāniyya d'Ibn al-Ṭiqțaqā, Kitāb al-Kharaj, etc.), les traditions juridiques (sharīat-nāma, al-fiqh al-dastūrî), les anthologies d'adab comme par exemple les 'Uyān al-akhbār d'Ibn Qutayba et, enfin, les miroirs des princes. Mohsen Zakeri effectue dans cette dernière catégorie de textes une classification : 1) andarz-nāma, pand-nāma, 2) Āyīn-nāma, 3) fables du type Kalìla wa dimna, 4) narration épique, genre Khudāy-nāma, Shāh-nāma, 5) fiction genre Sindbād-nāma et enfin 6) les textes de littérature populaire (Samak-i 'Ayyār, Dārāb-nāma, Abū Muslim-nāma). L'insertion par Mohsen Zakeri de ce type de littérature dans la catégorie éthique gouvernementale et son analyse de Samak-i 'Ayyār sont particulièrement prometteurs.

La perspective comparative entre christianisme et islam affirmée par les éditrices aurait été mieux perceptible si une conclusion synthétique clôturait le volume. Cette publication accompagnée d'un index est néanmoins un apport significatif aux études sur la littérature d'éthique gouvernementale et de conseils aux princes. 


\section{AUTEURS}

DENISE AIGLE

UMR 8167 - Orient et Méditerranée 